\title{
BIVALVE SHELL TAPHONOMY IN TROPICAL SILICICLASTIC MARINE ENVIRONMENTS: PRELIMINARY EXPERIMENTAL RESULTS
}

\author{
BEST*, Mairi M.R. and KIDWELL, Susan M., Department of the Geophysical \\ Sciences, University of Chicago, 5734 S. Ellis Avenue, Chicago, IL 60637, U.S.A.
}

While the post-mortem behavior of bivalves has been explored in a number of temperate siliciclastic environments and tropical carbonate environments, little is known of tropical siliciclastic environments. Possible differences with previously studied areas might arise due to: rates of microbial decay (e.g.. related to differences in maximum temperature and seasonality), rates of acid evolution, and rates of sedimentation and therefore burial.

In November 1994, we deployed three experimental bivalve shell arrays (for retrieval after 1, 2, and 3 years) in each of five shallow water sites in the siliciclastic Bocas del Toro area of Caribbean Panama. Each array consisted of a PVC "tripod" anchored to a large cement block, with one arm oriented perpendicular to the seafloor and the other 2 oriented parallel to and just above the sediment-water interface. Airdried pre-drilled shells of known age-since-death (purchased live) were a) attached by cable-ties to the vertical arm to test for taphonomic damage during continuous exposure above the seafloor, or b) attached to fishing line strung loosely between the two horizontal arms so that shells could go through natural cycles of shallow burial and exhumation. We used shells from two North American commercial species (Mercenaria mercenaria, Mytilus edulis ) because these provide microstructures common in tropical faunas, are readily available, and are obvious "exotics" in tropical death assemblages should they become detached from the experimental arrays.

In November 1995, we successfully relocated 4 of the original 5 array sites. At one of these 4 sites (Callianassa-burrowed carbonate sand), PVC tripods had been snipped from anchor blocks. Failure to relocate the 5 th array site is attributed to poor visibility $(<1 \mathrm{ft}$.) and a dearth of useful landmarks in that seagrass habitat. Shells from the 3 retrieved arrays (mangrove mud in $4 \mathrm{~m}$ water depth, sandy mud by patch reef in $5 \mathrm{~m}$, soft mud in $7 \mathrm{~m}$ ) show differences in encrustation and surface degradation.

A. All specimens held above the sediment/water interface had heavy encrustation (90$100 \%$ in mangrove mud, $\sim 75 \%$ in other sites); cementing oysters, Chama, barnacles, and serpulids were the first colonists, followed by sheet bryozoans, sponges, ascidians, and soft green algae; many of these have a high preservation potential in the fossil record. This order of colonization contrasts with the soft-tissued and primarily photosynthetic taxa that usually colonize dead shells first in pure carbonate settings. B. Specimens tethered to fishing line showed much less but still appreciable encrustation (up to $30 \%$ ) in all but the mangrove site, suggesting a certain variability in burial histories; and all showed significant surface degradation (interior surfaces). On some Mytilus all nacre was gone and the prismatic calcite layer was damaged; the ligament and part of the periostracum were still present. Mercenaria specimens were both chalky and pitted inside the pallial line, but only chalky outside the pallial line (porcellaneous aragonites); prismatic aragonite of the myostracum was pristine, and the ligament was still present. This variation among microstructural sectors was most pronounced on shells with little or no encrustation, indicating the importance of burial in generating this type of damage. Preferential destruction of nacre is consistent with microstructural breakdown being accelerated by relatively large amounts of intercrystalline organic matrix (also seen in earlier lab experiments), but the macroscopically pristine appearance of myostracum in array specimens (and in local death assemblages) is puzzling. 